\title{
Technique
}

\section{Median sternotomy - gold standard incision for cardiac surgeons}

\author{
Radu Matache ${ }^{1,2}$, Mihai Dumitrescu ${ }^{2}$, Andrei Bobocea ${ }^{2}$, Ioan Cordoș ${ }^{1,2}$ \\ ${ }^{1}$ Carol Davila University, Department of Thoracic Surgery, Bucharest, Romania \\ ${ }^{2}$ Marius Nasta Clinical Hospital, Department of Thoracic Surgery, Bucharest, Romania
}

\begin{abstract}
Sternotomy is the gold standard incision for cardiac surgeons but it is also used in thoracic surgery especially for mediastinal, tracheal and main stem bronchus surgery.

The surgical technique is well established and identification of the correct anatomic landmarks, midline tissue preparation, osteotomy and bleeding control are important steps of the procedure.

Correct sternal closure is vital for avoiding short- and long-term morbidity and mortality. The two sternal halves have to be well approximated to facilitate healing of the bone and to avoid instability, which is a risk factor for wound infection.

New suture materials and techniques would be expected to be developed to further improve the patients evolution, in respect to both immediate postoperative period and long-term morbidity and mortality
\end{abstract}

Keywords: median sternotomy, cardiac surgeons, thoracic surgery, technique 


\section{Introduction}

Median sternotomy was introduced by Milton in 1897 and has since become the standard incision in cardiac surgery allowing for access to the mediastinum and pleural cavities (1).

In thoracic surgery the incision is used for tumor resections of the anterior mediastinum, lower trachea and main stem bronchus surgery as well as retrosternal goiters or for the management of vascular lesions $(2,3)$.

Sternotomy can also be used in combination with left or right thoracotomy as an upper or lower partial sternotomy due to the reduced morbidity and mortality by sternal dehiscence. The use of sternotomy in trauma patients for the management of heart and great vessel lesions is limited thoracotomy is more frequently used by thoracic surgeons (3-5).

\section{Technique}

The sternum is responsible for the stability of the chest, which is the precondition of physiological respiration. An unstable sternum can result in wound infection and significant morbidity.

\section{Patient preparation}

The patient is positioned in supine position with the arms secured alongside him and a roll between the scapulae. The upper torso is shaved, antibiotic prophylaxis is given within one hour of the incision and the patient is draped with sterile film $(2,3)$.

\section{Incision}

The jugulum and xiphoid are marked and linea alba is incised (Figure 1). The incision has to be a median and vertical line between the sternal notch and the tip of the xiphoid process. The midline

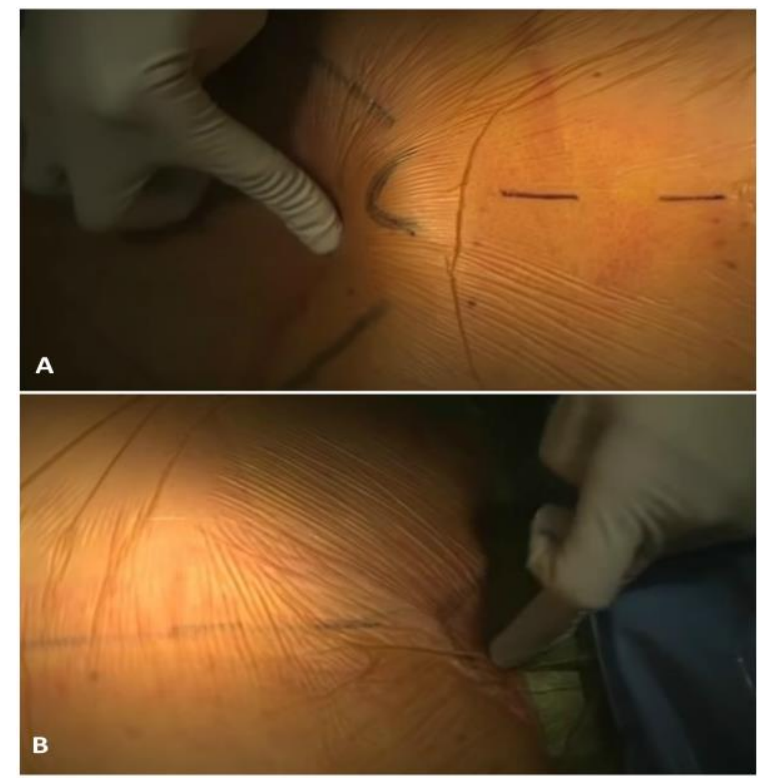

Figure 1. Identifying the xyphoid (A) and sternal notch $(B)$ before incision

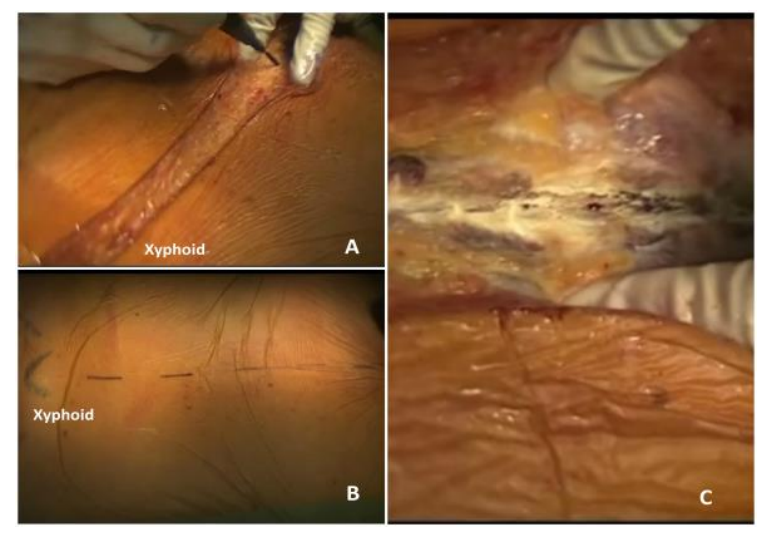

Figure 2. Incision of the skin, cutaneous layer $(A)$ and periosteum $(C)$ according to landmarks $(B)$

can be easily incised with cautery between these two landmarks by dividing the subcutaneous tissue and the underlying pectoral fascia between the fibres of the pectoralis major muscle (Figure 2).

In select patients the incision can be limited to an upper sternotomy or manubriotomy which starts from the sternal notch, and continues down to just below the angle of Louis. This limited incision is used for surgery of the mediastinal goiters, surgery of the trachea and minimally invasive aortic and mitral valve repair. From here 
the incision is extended toward the right fourth rib. The periosteum is divided and bleeding points are cauterized with the electrocautery. Next, the tissue is cauterized from the fourth rib up to the pectoralis major muscle before dividing the sternum for a length of up to $10 \mathrm{~cm}(6,7)$.

The sternal periosteum is then separated, while at the same time cauterizing bleeding points, being careful not to strip the periosteum as this may cause difficulties with healing.

Identification and division of the transverse venous arch in the jugulum is mandatory in order to avoid bleeding. The interclavicular ligament of the sternal notch, which is located at $0.5 \mathrm{~cm}$ below the surface, is divided next with the cautery.

The third step is blunt digital dissection of the posterior side of the sternum from the underlying sternoclavicular ligament. The final step before sawing is blunt digital dissection of the xyphoid process from the underlying tissue of the diaphragm. Blunt digital dissection carries no risk and ensures the blade of the sternal saw doesn't come in contact with the underlying tissue.

The sternum is usually divided from top to bottom by using a sternal saw (Figure 3) but it can also be performed from the bottom to the top (2, $3)$.

\section{Osteotomy}

After preparation of the jugulum, the xiphoid and the midline, the surgeon is prepared to saw the sternum. Before sawing, the anaesthesist is asked to stop ventilating the lungs in order to avoid accidental opening of the mediastinal pleura with the saw. Usually, the osteotomy is performed from above downwards and the saw is oriented upwards in order to avoid injury to underlying structures such as pleura, pericardium, innominate vein or brachiocephalic artery $(1-3,8)$.

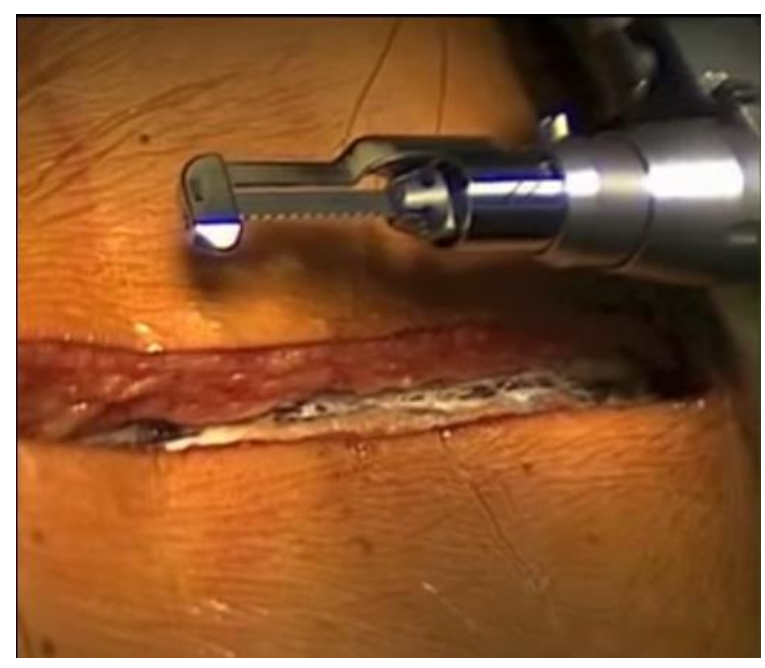

Figure 3. Electric sternal saw activated by foot pedal

The exposed periosteum will led to bleeding which can be controlled with the cautery and bone wax for sealing the bone marrow. It is worth noting that excessive cauterization of the periosteum may lead to necrosis and wound infection, while an excessive amount of wax prevents ossification. Some surgeons use only towels placed over the sternal edges to control the bleeding (Figure 4).

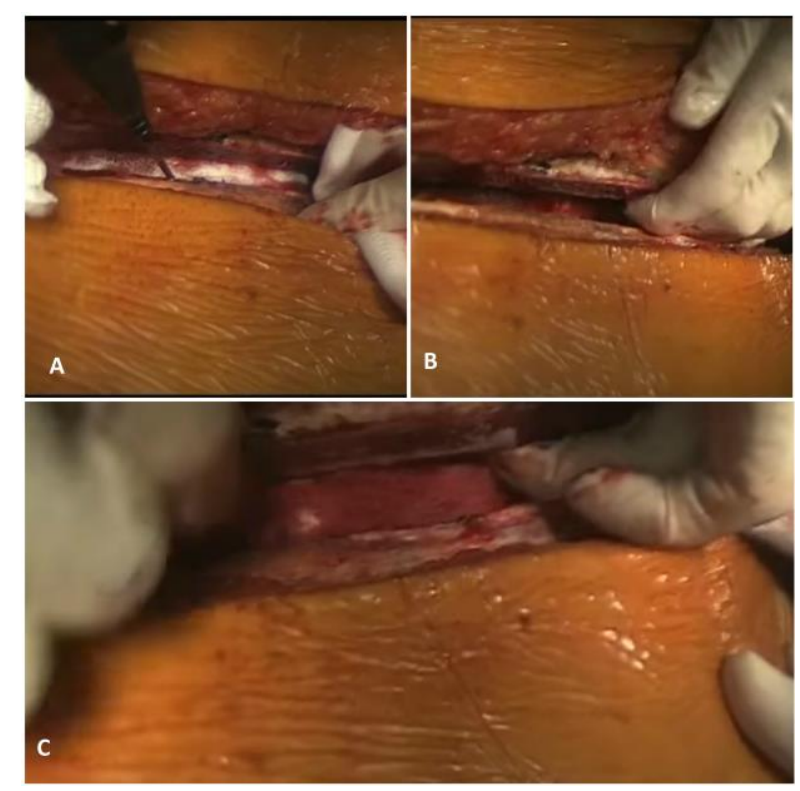

Figure 4. Control of the bleeding after sternotomy with cautery $(A)$ and wax (B and $C$ ) 


\section{Retraction}

The sternum is retracted slowly and progressively in order to avoid fractures. Initially the sternum will be retracted manually until there is enough room to insert a Finnocheto retractor. Towels can be placed around the sternal edges for bleeding control and protection from retraction trauma. During retraction the sternopericardial ligaments are freed passively from the posterior surface of the sternum (Figure 5).

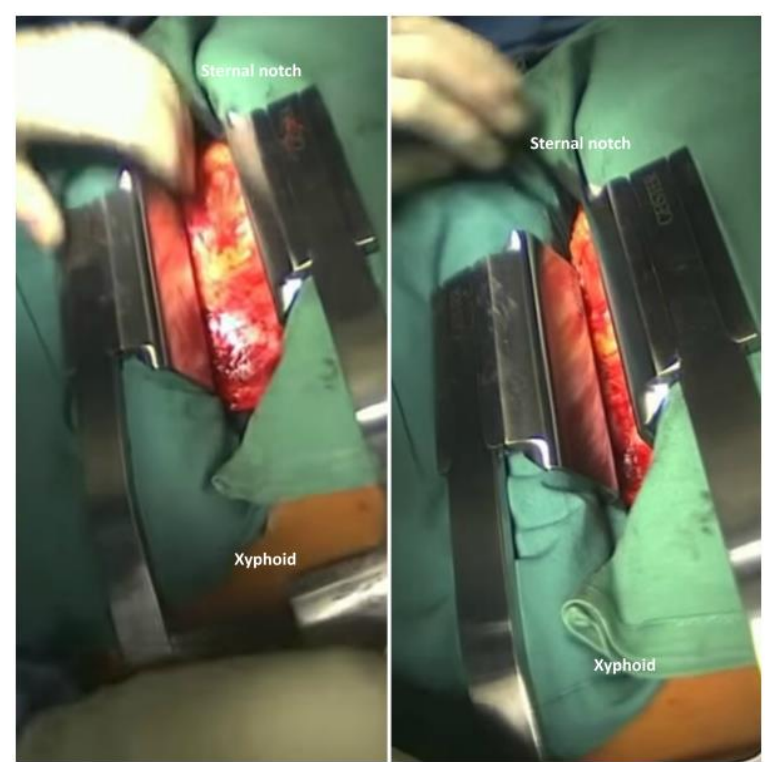

Figure 5. Gradual opening of the sternum with Finochetto retractor.

\section{Chest tubes}

At the end of the procedure, mediastinal and/or pleural tubes are placed through stab incisions in the epigastrium. It is important to place the tubes below the fascia of the rectus muscle to avoid herniation and not too far from the median line as to avoid injury of the epigastric vessels. The retrosternal chest drains are removed when drainage is serous and below $100 \mathrm{ml} /$ day.

\section{Sternal closure}

To protect the heart during insertion of the wires, a towel is placed between the sternal halves. The wires can be made from stainless steel (for benign conditions such as tracheal stenosis) or silk (in patients with mediastinal tumors requiring radiation therapy), either singular or figure of eight.

The number of wires used for closure depends on the patients weight and height, and varies from 6 to 10 , but as a general rule we use one wire for every $10-15 \mathrm{~kg}$ of the patients weight. Two-three wire sutures are placed around the manubrium and four-six are placed around the edges of the body of the sternum.

The wires can either be passed through the sternal bone, perpendicularly in order to create a passage with minimal bleeding, or parasternal, through the intercostal space but with the risk of injuring the internal thoracic pedicle or intercostal bundle. The wires must be placed at equal distance from each other in order to avoid an override or shift of the sternal edges. After all wires have been set, the towel is removed carefully while lifting the wires upwards $(9,10)$.

Before closure, the mediastinum is rinsed with saline solution and both retrosternal halves are checked for bleeding. The surplus wax must be removed before closure and some surgeons even remove the initially used bone wax from the spongiosa in order to prevent healing complications (9).

While approximating the sternal halves, it is important not to apply too much force as to avoid horizontal fractures of the sternum. After proper approximation, the wires are twisted until the sternal halves are tightly re-approximated. It is important not to over-twist the wires because they can easily brake (Figure 6). The twisted ends must 
not be too long, usually less than half of we recommend to patients to wear a thoracic vest centimeter, and have to be buried into the for stabilization for 4-6 weeks $(9,10)$.

presternal tissue because they may cause skin erosion or perforation (10).

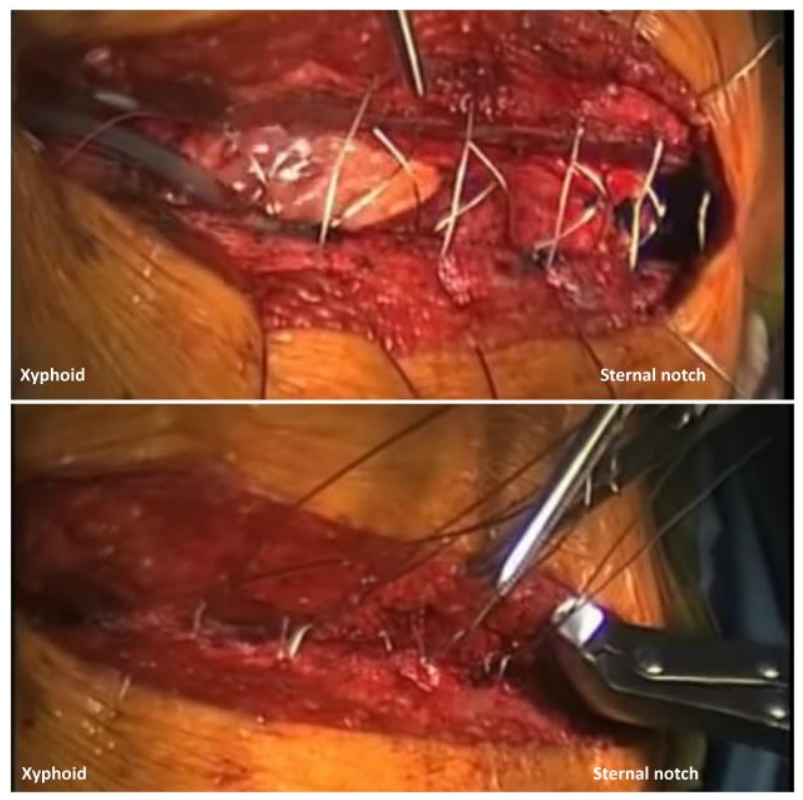

Figure 6. Closure of the sternum using stainless steel wires.

Inappropriate sternal approximation can cause postoperative pain and dehiscence, which is a risk factor for wound infection. The tissues, including the pectoralis fascia, are then closed in separate layers with resorbable running sutures. The skin is closed either with an absorbable running suture or with clips (2).

\section{Wound care}

The wound is cleaned with iodine and the dressing will not be removed until 5 days postoperatively.

\section{Sternal care}

The risk factors identified for sternal wound infection and instability are body mass index $>30$, chronic obstructive pulmonary disease, bilateral mammary harvesting, >75 years of age and diabetes. In order to keep the sternum stabilized

\section{Outcome \& Discussion}

The advantages of sternotomy are that it can be performed rapidly and allows excellent exposure for all pathologies situated in the anterior and middle mediastinum. The disadvantages of sternotomy are the long midline scar and the possibility of sternal instability, lifethreatening osteomyelitis and mediastinitis (2).

Complications, such as sternal dehiscence with instability and wound infections, are rare if sternotomy and sternal closure are performed properly, and depend more on patient-related risk factors.

\section{Infection and dehiscence}

Infections can be either superficial or deep. The incidence rate of the former is reported to be between 3 and $8 \%$, while for the latter, mediastinitis has been reported to occur at a rate of only $1-3 \%$ and is associated with high mortality rate of up to $35 \%(2,3)$.

The incidence of sternal wound infection and dehiscence is increased by advanced patient age, diabetes, obesity, smoking, steroid therapy, excessive cauterization, prolonged surgery, reintervention and chronic obstructive pulmonary disease. Patients with sternal wound infection often have fever, leukocytosis, sternal clicking noise, movement during respiration, purulent discharge from the sternal wound, sternal dehiscence and retrosternal effusion (2) (Figure 7). 


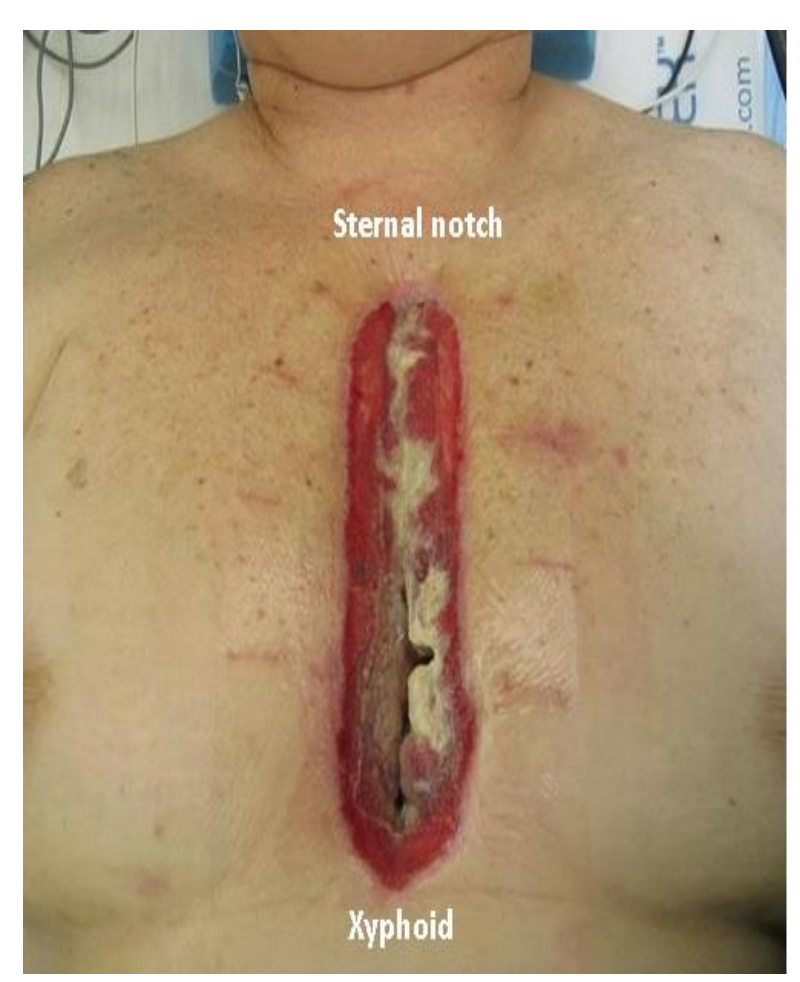

Figure 7. Obese female patient with sternal wound dehiscence and infection

Sternal dehiscence generally manifests 3-5 days postoperatively with a sero-sanguineous leak from the sternal wound and sudden wound opening on straining. The patient may be treated with wound debridement and sternal rewiring, although conservative management with vacuumassisted closure therapy is also an option but with some risks $(1,11,12)$.

\section{Sternal instability and pseudoarthrosis}

After surgery approximately $1-2 \%$ of patients present signs of sternal instability like costochondral pain, clicking noise during movement, and palpable instability on coughing. These patients are at risk of developing a sternal wound infection but most cases resolve favorably by pseudoarthrosis (1).

\section{Brachial plexus injury}

Brachial plexus injury has been reported as a consequence to sternal retraction but the complication is extremely rare and diagnosis requires electromyogram studies. Treatment involves the use of analgesics and physiotherapy (1).

\section{Keloid and hypertrophic scars}

Hypertrophic scarring is frequent and keloid scars are more frequent in African population (1).

\section{Conclusions}

Sternotomy is the gold standard incision for cardiac surgeons but it is also used in thoracic surgery especially for mediastinal, tracheal and main stem bronchus surgery. The surgical technique is well established and identification of the correct anatomic landmarks, midline tissue preparation, osteotomy and bleeding control are important steps of the procedure. Correct sternal closure is vital for avoiding short- and long-term morbidity and mortality. The two sternal halves have to be well approximated to facilitate healing of the bone and to avoid instability, which is a risk factor for wound infection.

\section{References}

1. Iriz E, Erer D, Koksal P, Ozdogan ME, Halit V, Sinci V, Gokgoz L, Yener A. Corpus sterni reinforcement improves the stability of primary sternal closure in high-risk patients. Surg Today. 2007; 37(3): 197-201. PMID: 17342356 https://doi.org/10.1007/s00595-0063376-5

2. Staveski S, Abrajano C, Casazza M, Bair E, Quan H, Dong E, Petty A, Felix K, Roth SJ. Silver-Impregnated Dressings for Sternotomy Incisions to Prevent Surgical Site Infections in Children. Am J Crit Care. 2016; 25(5): 402-8. PMID: 27587419

\section{https://doi.org/10.4037/ajcc2016843}


3. Ghorpade N, Hill D, Mohajeri M. Alternative for primary pericardial closure: sentry for reentry. Heart Lung Circ. 2004; 13(1): 52-5. PMID: 16352168

https://doi.org/10.1016/j.hlc.2004.01.008

4. Kalliomäki ML, Puolakka P, Huhtala H, Sisto T, Järvelä K. Bedside diagnosis of persistent post-sternotomy pain. Acta Anaesthesiol Scand. 2016; 60(7): 969-76. PMID: 26919717 https://doi.org/10.1111/aas.12704

5. Atluri P, Stetson RL, Hung G, Gaffey AC, Szeto WY, Acker MA, Hargrove WC. Minimally invasive mitral valve surgery is associated with equivalent cost and shorter hospital stay when compared with traditional sternotomy. J Thorac Cardiovasc Surg. 2016; 151(2): 385-8. PMID: 26432722

https://doi.org/10.1016/j.jtcvs.2015.08.106

6. Meszaros K, Fuehrer U, Grogg S, Sodeck G, Czerny M, Marschall J, Carrel T. Risk Factors for Sternal Wound Infection After Open Heart Operations Vary According to Type of Operation. Ann Thorac Surg. 2016; 101(4): 1418-25. PMID: 26652136

https://doi.org/10.1016/j.athoracsur.2015.09.0 $\underline{10}$

7. Ferreira RT, Silva RR, Marchi E. Aortic Valve Replacement: Treatment by Sternotomy versus Minimally Invasive Approach. Braz J Cardiovasc Surg. 2016; 31(6): 422-427. PMID: 28076618 https://doi.org/10.5935/1678-9741.20160085

8. Zencir G, Eser I. Effects of Cold Therapy on Pain and Breathing Exercises Among Median
Sternotomy Patients. Pain Manag Nurs. 2016; 17(6): 401-410. PMID: 27746091

https://doi.org/10.1016/j.pmn.2016.05.006

9. Bek EL, Yun KL, Kochamba GS, Pfeffer TA. Effective median sternotomy closure in highrisk open heart patients. Ann Thorac Surg. 2010; 89(4): 1317-8. PMID: 20338376 https://doi.org/10.1016/j.athoracsur.2009.05.0 $\underline{57}$

10. Huang AP, Sakata RK. Pain after sternotomy review. Braz J Anesthesiol. 2016; 66(4): 395401. PMID: 27343790

\section{https://doi.org/10.1016/j.bjane.2014.09.013}

11. van Wingerden JJ, de Mol BA, van der Horst CM. Defining post-sternotomy mediastinitis for clinical evidence-based studies. Asian Cardiovasc Thorac Ann. 2016; 24(4): 355-63. PMID: 26970253

\section{https://doi.org/10.1177/0218492316639405}

12. Sjogren J, Gustafsson R, Nilsson J, Lindstedt S, Nozohoor S, Ingemansson R. Negativepressure wound therapy following cardiac surgery: bleeding complications and 30-day mortality in 176 patients with deep sternal wound infection. Interact Cardiovasc Thorac Surg. 2011; 12(2): 117-20. PMID: 21106567 https://doi.org/10.1510/icvts.2010.252668

13. Carlesimo B, Lo Torto F, Rossi A, Marcasciano M, Ruggiero M. Long-term result of bilateral pectoralis major muscle advancement flap in median sternotomy wound infections. Eur Rev Med Pharmacol Sci. 2014; 18(24): 3767-72. PMID: 25555865

14. Wu S, Wan F, Gao YS, Zhang Z, Zhao H, Cui ZQ, Xie JY. Sternal reconstruction of deep 
sternal wound infections following median sternotomy by single-stage muscle flaps transposition. Chin Med Sci J. 2014; 29(4): 208-13. PMID: 25429744

https://doi.org/10.1016/S1001-9294(14)60072-9

15. Murzi M, Miceli A, Di Stefano G, Cerillo AG, Farneti P, Solinas M, Glauber M. Minimally invasive right thoracotomy approach for mitral valve surgery in patients with previous sternotomy: a single institution experience with 173 patients. J Thorac Cardiovasc Surg.
2014; 148(6): 2763-8. PMID: 25224550

https://doi.org/10.1016/j.jtcvs.2014.07.108

16. Sawaki S, Ito T, Maekawa A, Hoshino S, Hayashi Y, Yanagisawa J, Tokoro M, Ozeki T. Outcomes of video-assisted minimally invasive approach through right minithoracotomy for resection of benign cardiac masses; compared with median sternotomy. Gen Thorac Cardiovasc Surg. 2015; 63(3): 142-6. PMID: 25085318 https://doi.org/10.1007/s11748-014-0456-0 